lenses are too expensive to be available to the mass of prospective wearers and that some less expensive lens is needed. This argument is raised in support of the makeshift lenses which I condemn. My reply is that these lenses are no less expensive, either because their cost cannot or will not be reduced. It appears to me that the only way of making satisfactory moulded lenses available at the minimum cost is to have as many practitioners as possible who are trained to fit these in the minimum number of sessions of actual fitting. One could not hope to mass-produce dentures in order to reduce their cost. Why should we expect to achieve this in the realm of contact lens work?

\title{
Summary
}

Corneal veiling must not be treated as an isolated symptom but is inevitably bound up with the subject of fitting. It is due to defects in fitting which give rise to circulatory obstruction of varying degrees of severily, or to stagnation of the precorneal fluid, or to both'. Stagnation of the precorneal fluid alone will give rise to slight veiling without intolerance, the veiling being usually only noticed in artificial light. When combined with circulatory embarrassment, veiling is more severe and is accompanied by irritability and intolerance. The remedy lies in correcting or avoiding the defects, not in relieving their consequences by drilling holes in the lens. All the untoward symptoms associated with contact lenses, veiling included, can be avoided by bringing the practice of fitting out of the academic and theoretical clouds down to solid earth.

\section{A PRELIMINARY NOTE ON A NEW METHOD OF FIXING CORNEAL GRAFTS}

\author{
BY \\ C. A. PitTaR \\ AUCKLAND, NEW ZEALAND
}

I DID not intend to publish this small work until I had sufficient cases to demonstrate its usefulness or otherwise. With the present lack of donor grafting material in New Zealand, however, opportunity for these operations is infrequent; and as the method appeared so successful in the cases I have done, I decided to make this preliminary note.

In 1941 this method first occurred to me while considering the 
technique of keratoplasty in general. It seemed to me that it would often be an advantage to have a fairly big graft ( 5 to 6 $\mathrm{mm}$.). To get consistently good results and avoid anterior synechiae, one would have to aim at a water-tight joint. The ideal would appear to be perfectly clean-cut corneal discs of equal size from the donor and recipient, with no attempt at bevelling. If this were possible, the graft would fit like a plug, and would tend to be thrust out by the re-forming aqueous under intraocular pressure. There would be no tendency for it to go into the anterior chamber unless there was escape of aqueous allowing it to tilt. For these ideals a circular graft would theoretically be preferable to a square one.

This ideal would obviously be difficult to attain, and there would often be irregularities, at least in the deeper portion of the recipient cornea. Thus there would not always be a perfect fit, and so the aqueous would tend to leak. If the fit were perfect, the ordinary criss-cross sutures would hold the graft satisfactorily, and there would be no leak. With, suture fixation, however, there would be nothing to prevent a leak at any irregular or weak point.

How then to improve on the existing methods of fixation in preventing aqueous leakage? The simplest method seemed to be to have something to cover the whole wound, slightly overlapping the cornea on each side and firmly fixed to the eye-ball. Some non-irritant metal unaffected by body fluids seemed most suitable. The idea was to have a ring made out of thin sheet metal $1.5 \mathrm{~mm}$. wide; of such a circumference as to overlap the trephine cut by $0.75 \mathrm{~mm}$. on each side, and with four arms 1.5 $\mathrm{mm}$. wide to reach just beyond the limbus with notches cut near the ends of the arms for sutures tied round them to grip. The whole was to conform to the curvature of the cornea, the ends of the arms altering their curvature slightly as they came on to the sclera, where they were to be sutured, thus avoiding all sutures in the cornea.

My first experimental " corneal splint" was made of platinum. I made a cast of a rabbit's eye to which a thin sheet of platinum was moulded, and from which the splint was then cut. I experimented with dead rabbits' eyes, comparing this fixation with the various suture methods, and increasing the intra-ocular pressure by injecting saline. I also tried using egg-membrane between the cornea and splint as an extra seal against leakage, but the splint alone seemed to give sufficient closure. I was then preparing to do some research with live rabbits, but this was prevented by my being moved to another naval station, and I was unable to do any more until after the war. Then return to 
civilian practice left little time for research, but eventually, after some further experimenting, I devised the present splints and trephine guides, which I shall describe.

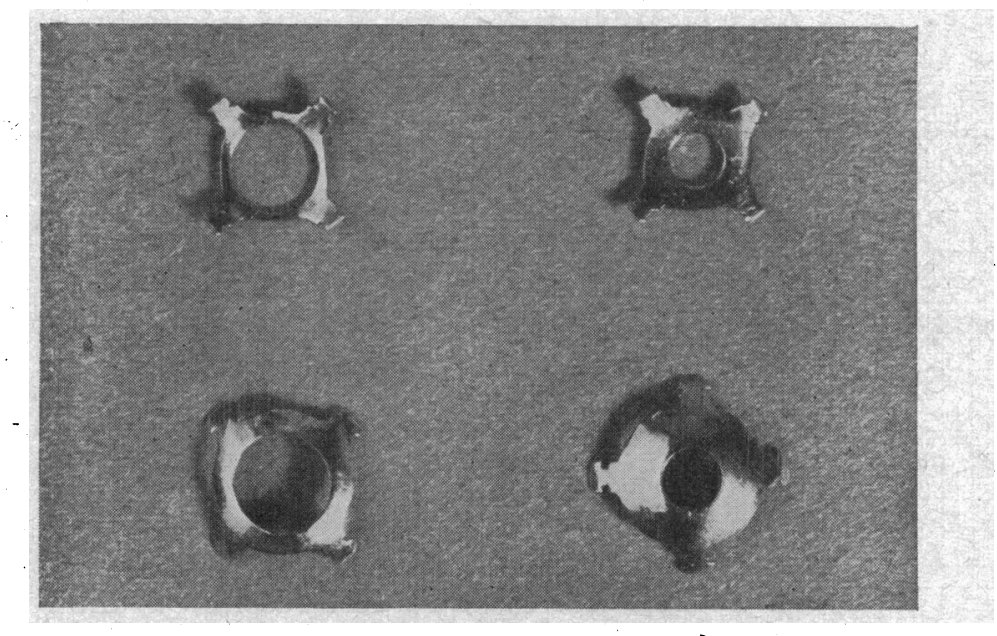

Fig. 1.

Top. Guide and Splint used in Case No. 2 (Corneal surface)

Lower. Guide and Splint used in Case No. 3. (Outer surface)

I have modified my original splint, shortening the arms so that they end over the cornea near the limbus. This is preferable to carrying them on to the sclera because

(1) Corneae vary in diameter, and also in length of different axes.

(2) It simplifies the making of the splint accurately, and leads to a better fit.

(3) There seems no contra-indication to placing sutures in the cornea well away from the wound, and in my experience they are more easily and more accurately placed than in the sclera with overlying conjunctiva.

Then there is the trephine guide, which is an essential in this method. It is an exact replica of the splint; except that the central aperture is enlarged so that it will just permit the entry of the trephine.

At operation the guide is first placed on the cornea. Then while it is held there, a suture is placed in the cornea beneath the end of each arm of the guide. These four sutures are tied once without completing the knot. This will hold the guide firmly in place. The trephine is then placed in the aperture in the guide 
and a cut made-perhaps one-third of the way through the cornea. It is then removed, and the guide also removed after loosening but not undoing the suture-loops. The trephining is then completed in the usual manner. When the graft is put in place the splint is immediately applied, and the sutures tightened over the arms and the knots completed. We know that the splint will exactly cover the trephine cut with an equal overlap on each side without having to fit or measure it, because of the calculated association of the dimensions of the guide and splint.

The present splints and guides are made of platinized gold, and are of a thickness of $0.2 \mathrm{~mm}$.

The pair used in case No. 2 were for a $4.5 \mathrm{~mm}$. graft and of the following dimensions :

$$
\begin{array}{lrr}
\text { Splint-Internal diameter } & =3 & \mathrm{~mm} . \\
\text { External diameter } & =6 & \mathrm{~mm} . \\
\text { Overall diameter (end of arm to end of arm) } & =10 & \mathrm{~mm} . \\
\text { Guide-As above except that internal } & \\
\text { diameter } & =4.75 & \mathrm{~mm} .
\end{array}
$$

As there was no apparent unfavourable reaction to the foreign body (splint), and the patient felt no discomfort whatever, it seemed to me that it would not matter if a larger area of cornea were covered by a broader splint. Thus one could make a universal splint instead of having to have separate ones for each size of graft. With the guides it might be best to have separate ones for each size of trephine, or else one could possibly use a guide for the largest trephine, and use collars to centre smaller trephines.

For case No. 3 the following splint and guide were used :-

Splint-Internal diameter $=3.5 \mathrm{~mm}$. External diameter $=8.5 \mathrm{~mm}$.

Overall diameter (end of arm to end of arm) $=11.5 \mathrm{~mm}$. Guide-As above except that internal

$$
\text { diameter }=5.5 \mathrm{~mm} \text {. }
$$

It will be seen that the above splint could be used for grafts between 5 and $7 \mathrm{~mm}$. diameter, allowing a minimum overlap on the graft at one end of the recipient cornea, at the other of $0.75 \mathrm{~mm}$.

\section{Notes on Three Cases of Corneal Graft}

I have only done three cases between December, 1947 and November, 1948, but they will serve to illustrate some points I have observed. In the first case I used sutures as described by Katzin (1947), and in the last two cases I used my corneal splint.

The first case gave me some anxiety, as he formed an anterior synechia. This, 
however, I was able to free on the 18th day after the keratoplasty with a discission needle entered at the limbus without opening the wound. The graft did not become vascularised, but was slightly hazy from epithelial bedewing. The tension, however, was not appreciably raised to fingers-certainly not enough to account for bedewing as usually seen. Therefore I did not suspect glaucoma at

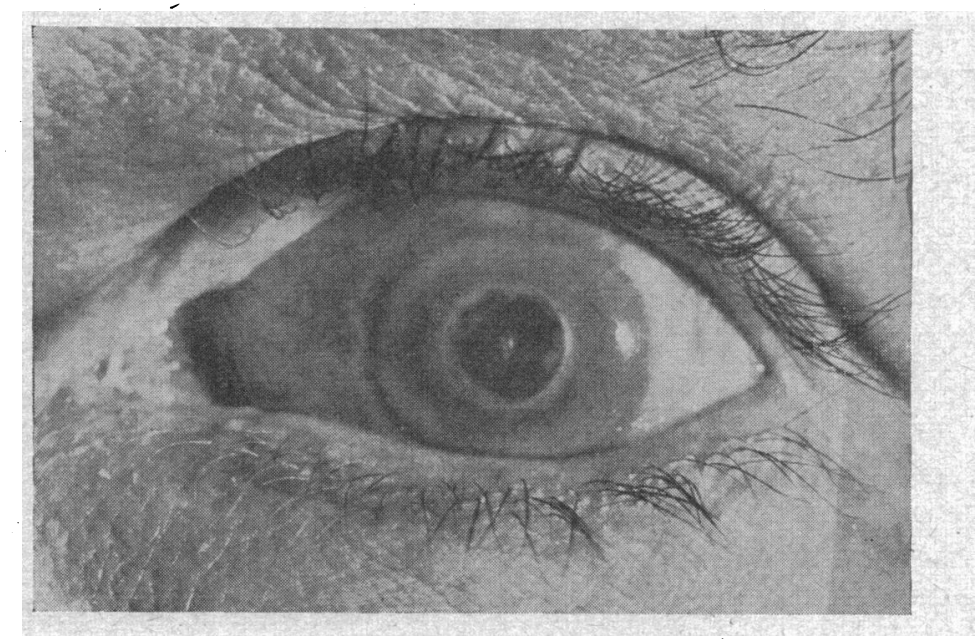

FIG. 2

Case No. 1. Fifteen months after operation. Photogräph poor, as it distorts the cornea and shows image of camera in centre of graft. Actually vision is $6 / 12$ to $6 / 9$ and Jaeger 1 .

first buit eventually I took the tension with a Schiötz tonometer, and found it to be slightly though definitely raised $(30 \mathrm{~mm}$. of $\mathrm{Hg}$. as compared with $17 \mathrm{~mm}$. in the other eye). I did a corneo-scleral trephine after which the cornea cleared completely, and the patient now has $6 / 12$ to $6 / 9$ vision with correction. It would seem from this that a corneal graft may be liable to develop epithelial bedewing at a considerably lower intra-ocular pressure than would a normal cornea.
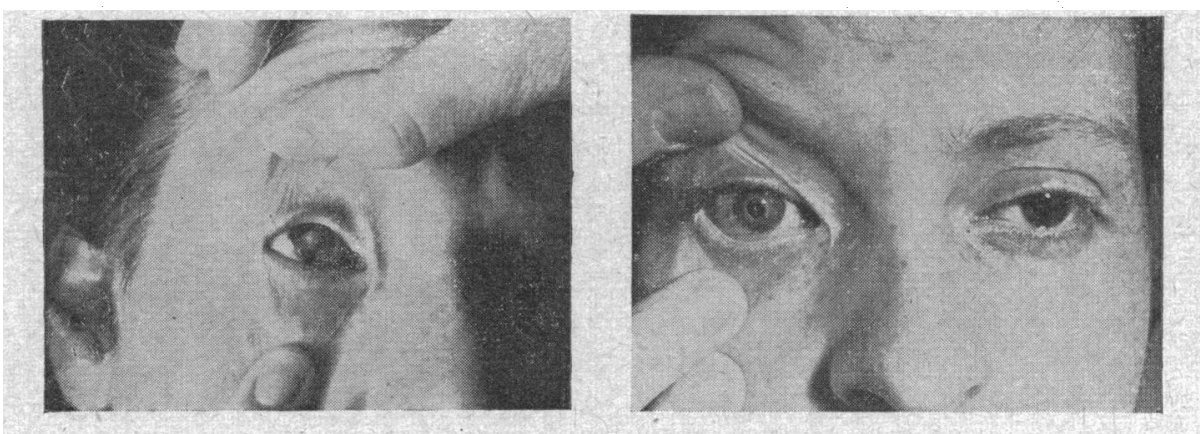

FIG. 3 .

Case No. 2. A, Before operation, showing dense leucoma; and $B$, one month after operation, showing clear $4.5 \mathrm{~mm}$. graft. 
The last two cases in which corneal splints were used have been uneventful, with excellent healing and quick re-formation of the anterior chamber. The third case was a $5 \mathrm{~mm}$. disc, and after the trephine the iris contracted abnormally, so that the whole pupil and much of the iris lay within the trephine circle, but no anterior synechiae formed. That suggests quick reformation of the anterior chamber with no appreciable leak.

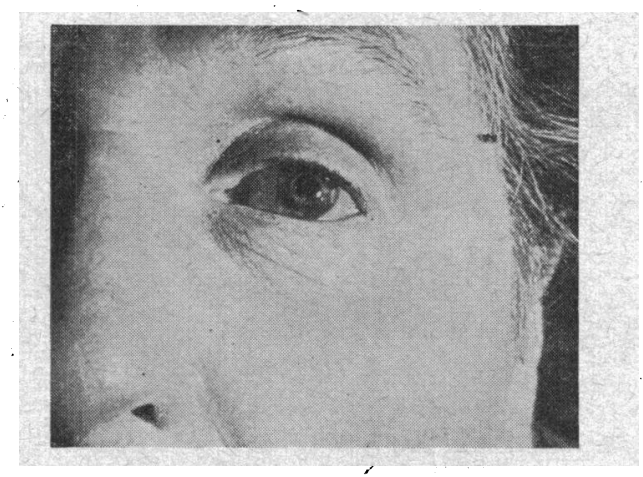

FIG. 4.

Case No. 3. One month after operation, showing clear $5 \mathrm{~mm}$. graft. Note white marks near limbus indicatıng site of sutures that held splint in place.

Pain was absent, and there appeared to be no reaction to the splint in either case, nor was there any feeling of discomfort. In both cases the splints, when they were removed on the 7th day, were found covered by a film of mucus (a similar film was observed on the sutures in the first case) and there was no mark or indication as to where they had been touching the cornea. Therefore in future I think I shall be inclined to leave the splint on longer (ten days or more).

\section{Conclusion}

It seems to me that the following are the advantages of this method over other methods of fixing a corneal graft such as sutures, conjunctival flaps, etc. :-

(1) A more perfect sealing of the wound, together with prevention of tilting of graft.

(2) Prevention of sudden loss of anterior chamber after it has re-formed.

(3) Greater accuracy and even distribution of pressure over the whole wound.

(4) Simpler technique with assured perfect placing. The crisscross sutures are quite difficult to place accurately so that they all cross in the centre and spread the pressure equally round the circumference of the graft. 
(5) Nothing touches the central area of the graft, which is thus safe from possible injury, and a clear view is left of most of the graft and of the anterior chamber.

(6) I think it will be found that such strict rest for so long after the operation will not be necessary. With experience of more cases, I feel sure I shall be able to relax the restrictions with this method of fixation.

(7) It is appreciated that some cases for corneal grafting will have considerable astigmatism or flattening of the cornea, and it might be thought that this would militate against a good fit of the corneal splint. In reality this is not so, because when the four sutures are tied to the arms, the cornea is more or less made to conform to the natural corneal curve of the splint. In the third case some corneal astigmatism was actually observed, but that did not in any way interfere with the technique. If high astigmatism were encountered, the splint could be slightly bent to conform thereto.

\section{REFERENCES}

Amsler M. and Verrey, F. (1948).-Arch. d'Ophtal., 8, 150.

BRECHER (1947).-Analete Romano-Sovietice (Bucharest).-(Abstract Ophthal. Lit. 1, 4).

Castroviejo, R. (1932).-Amer J. Ophthal., 15, 825.

- (1941).-Ibid., 24, 1, 139.

- (1946).-Ibid., 29, 1081.

- (1948).-Trans. Amer. Acad. Ophthal. 53, 322.

Filatov, V. P. (1935).-Arch. of Ophthal., 13, 321.

Franceschetti, A. \& Doret M. (1947).-Bull. et Mém. de la Soc. franc. d'Ophtal., 59, 83.

HaRMs, H. (1948)-Klin. Monatsbl. f Augenh., 113, 59.-(Abstract Ophthal. Lit. 2, 3).

Katzin, H. M. (1947).-Arch. of Ophthal., 37, 379.

- (1947).-Arch of Ophthal., 38, 832.

McLean. I. M. (1948).-Trans. Amer. Acad. Ophthal., 53, 317.

Maumenee, A. \& E. Kokn blueth, W. (1948).-Trans. Amer. Acad. Ophthal., 53,331 .

Owens, W. C. et al (1948).-Trans. Amer. Acad. Ophthal., 53, 341.

Paton, R. T. 1947).-New England Ophthal. Soc.-reported in Amer. J. of Ophthal., 30, 1436.

(1948).-Trans. Amer. Acad. Ophthal.. 53, 312.

ThомаS, J. W. T. (1930).-Trans Ophthal. Soc. U.K., 50, 27.

- (1935).-Ibid., 55, 373.

- (1937).-Brit. Med. J. 1, 114.

- (1938).-Trans. Ophthal. Soc. U.K., 57, 520. 